\title{
O funcionamento discursivo da negação e da promessa no discurso religioso
}

Ercília Ana Cazarin*

\section{Resumo}

O texto ocupa-se com a análise do funcionamento discursivo da negação e da promessa no discurso religioso católico. Tem como corpus enunciados expostos em um cartaz sobre a obrigação dos fiéis pagarem o dízimo, afixado no interior da Catedral Basílica da Sé de Nossa Senhora de Assunção, em Mariana, MG, no ano de 2003. As análises colocam em evidência a divergência existente entre duas posições-sujeito no interior de uma mesma formação discursiva.

Palavras-chave: Negação. Promessa. Formação discursiva. Posição-sujeito. Interdição.
O texto analisa três enunciados (tomados como um texto) do campo do discurso religioso, expostos em um cartaz na Catedral Basílica da Sé de Nossa Senhora de Assunção, em Mariana, MG, no ano de $2003^{1}$. Eis os textos:

1 Não espere sobrar, ao receber a recompensa pelo seu trabalho, primeiro separe a parte de Deus. ESTE É SEU DÍZIMO².

2 Dízimo não é: doação, esmola, ajuda, pagamento, colaboração, oferta ou ato de piedade. Dízimo é: devolução a Deus do que já é de Deus!.

3 Todo o dízimo, apresentado no altar, retorna para o dizimista, multiplicado por Deus. ESTÁ NA BÍBLIA!

* Universidade Católica de Pelotas - UCPEL. Professora doutora do Programa de Pós-Graduação em Letras, inscrita na linha de pesquisa Texto, Discurso e Relações Sociais. E-mail: eacazarin@gmail.com.br

Data de submissão: abr. 2013 - Data de aceite: ago. 2013 http://dx.doi.org/10.5335/rdes.v9i2.3853 
A interpretação/análise que fazemos concebe o texto como um objeto linguístico-histórico a partir do qual podemos apreender o discurso que o sustenta. No caso em pauta, o texto foi empiricamente apresentado por três enunciados. A análise ancora-se na teoria da análise do discurso (AD), com filiação em Michel Pêcheux. Levando em conta que a linguagem não é transparente, a concebemos sob a dimensão sociohistórica, sempre atravessada pela ideologia e pelo inconsciente, que lhes são constitutivos. Portanto, o funcionamento discursivo ocorre determinado por elementos que vão além do linguístico. Em $\mathrm{AD}$, a materialização da língua pressupõe um sujeito que enuncia não na sua individualidade, e sim interpelado pela ideologia e descentrado pelo inconsciente. $\mathrm{O}$ sujeito da $\mathrm{AD}$ é um sujeito inscrito na história, e o sistema linguístico é concebido como um sistema significante, capaz de falhas que, para significar o que lhe é próprio, é afetado pelo real da história (pela contradição) - um sistema "pensado" no funcionamento da língua, com homens falando no mundo (ORLANDI, 2001, p. 40). Nesse sentido, a dispersão, a contradição, a incompletude, a falha, o equívoco constituem o real da língua e, tanto o imaginário quanto o real são intermediados pelo simbólico. O real é aquilo que não pode ser dito pela língua (pelo sistema), mas é apreendido pela discursividade, isso é, pela ordem do simbólico, mesmo sabendo-se que o real opõe-se ao simbólico e vice-versa.
Segundo Milner (1989, p. 55), o real da língua, , consiste na impossibilidade de se dizer tudo na língua, mas também é aquilo que lhe é mais próprio. Observamos, então, que o real da língua pode ser tomado como a língua em funcionamento, no qual há espaço para o possível e para o impossível. Este não está fora da língua - o impossível é apenas aquilo que não é aceito pelo sistema linguístico, é o que o sistema exclui, mas que nele emerge pelo viés da língua. Dizendo diferentemente: 0 acesso ao impossível se dá pelo possível - é no possível que se pode apreender o ponto da "falha, do equívoco etc. - costuma-se dizer que 'as palavras faltam'..." (LEANDRO FERREIRA, 2000, p. 26). É nessa perspectiva que o equívoco aparece como "o ponto em que o impossível (linguístico) chega a unir-se com a contradição (histórica) - esse é o ponto de encontro em que a língua toca a história" (GADET e PÊCHEUX, 1984, p. 63-64).

Realizada essa breve apresentação de alguns pressupostos da $\mathrm{AD}$, passamos a examinar o discurso religioso. Orlandi (1987, p. 239), ao tratar dos modos de funcionamento do discurso, assinala que a reversibilidade é a condição para que ele aconteça. Conforme a autora, precisamos ter presente que nem todo o discurso possui o mesmo grau de reversibilidade - no discurso polêmico, essa se pauta segundo certas condições; no lúdico, um discurso com elevado grau de polissemia, a reversibilidade está presente; já no autoritário, a mesma 
tende a zero, mesmo não havendo uma efetiva reversibilidade, é a ilusão de reversibilidade que sustenta esse discurso. $\mathrm{O}$ discurso autoritário tende à monossemia, no entanto, a autora citada lembra que não existe a possibilidade de reversibilidade zero, pois sem a dinâmica da reversibilidade na relação de interlocução, "o discurso não se dá, não prossegue, não se constitui”.

No caso em análise, estamos diante do discurso religioso o qual se caracteriza "como aquele que representa a 'voz de Deus". Isso se dá pela voz do padre, do pregador, ou, em geral, de qualquer representante seu - é um discurso sem autonomia, pois não admite modificações (op. cit. p. 243 e 245). "No discurso religioso, há um desnivelamento fundamental na relação entre locutor e ouvinte: $o$ locutor é do plano espiritual (o sujeito, Deus) e o ouvinte é do plano temporal (os sujeitos, os homens)" - de um lado, a onipotência de Deus, de outro, a submissão humana. Ocorre aí, segundo a autora, uma hierarquia, isso é, uma desigualdade em relação a esses dois sujeitos. E, "na desigualdade, Deus domina os homens" (ORLANDI, 1987, p. 243).

Nesse sentido, poderíamos entender que o discurso religioso tem fortes características do discurso autoritário, o qual segundo a autora (2001, p. 86), é "aquele em que a polissemia é contida, o referente está apagado pela relação de linguagem que se estabelece e o locutor coloca-se como agente exclusivo, apagando também sua relação com o interlocutor". Em texto distinto, já escrevia que a dissimetria entre o plano espiritual e o plano temporal funciona pelo uso de antíteses apoiadas no mecanismo gramatical da negação; quando a negação tem um efeito invertido, o não é o sim pressuposto no ouvinte. Então "a retórica do discurso religioso é a que se pode denominar retórica da denegação, ou seja, a negação da negação" (1987, p. 257).

$\mathrm{Na}$ análise dos enunciados, trabalhamos com as noções de negação e promessa, esta última normalmente acionada quando do funcionamento do discurso político, e a deslocamos para o âmbito do discurso religioso. No caso em pauta, entendemos estar diante da formação discursiva em que se inscreve o discurso religioso católico (FD do DRC), na qual convivem diferentes posições-sujeito, ainda que divergentes. Justificamos esse entendimento pelo fato de que o referido cartaz estava afixado no interior da igreja, o que nos leva a afirmar que a interlocução era buscada com os fiéis frequentadores da mesma, ainda que inscritos em uma posição-sujeito divergente.

$\mathrm{Na}$ análise, trabalhamos com duas posições-sujeito: 1. A posição-sujeito na qual se inscreve a voz da igreja, "a voz de Deus" representada, ainda que isso não esteja explicitado, por um sujeito enunciador identificado com a forma-sujeito da referida FD; 2. Uma posição-sujeito em que se inscrevem interlocutores, representados pelos fiéis. Posições essas 
que convivem, na divergência ${ }^{3}$, no interior de uma mesma formação discursiva, atestando a sua não homogeneidade de saberes, ou seja, a sua heterogeneidade constitutiva. Esse funcionamento discursivo não aponta para identidades ideológicas antagônicas, e sim evidencia que identidade ideológica não garante, necessariamente, posicionamentos idênticos. A relação da posição-sujeito 2 com a forma-sujeito da FD ocorre de uma forma tensa, evidenciando uma FD profundamente marcada pela contradição e pela heterogeneidade discursiva.

Entendemos que a noção de heterogeneidade discursiva, em $\mathrm{AD}$, constitui-se no momento em que Pêcheux aponta para a possibilidade da contradição e da transformação das relações entre sujeitos reguladas pelos aparelhos ideológicos de estado (AIE) tematizados por Althusser. No entanto, a referida noção ganha força a partir da contribuição de Authier-Revuz (1982), destacando-se a visão dialógica da enunciação e a teoria polifônica de Bakhtin, que estão na base teórica dos estudos de Authier. Além de Bakhtin, a autora recorre à releitura feita por Lacan da obra de Freud e estrutura a noção de heterogeneidade sob dois aspectos - a heterogeneidade mostrada e a heterogeneidade constitutiva $^{4}$ e articula a heterogeneidade do discurso ao descentramento do sujeito, o qual é apresentado, então, como efeito de linguagem e, por conseguinte, dividido, clivado, cindido (AUTHIER, 1982, p. 136). É esse aspecto, de um sujeito que não é uno, o cerne do conceito de heterogeneidade; essa mesma autora destaca que a heterogeneidade discursiva tem, na sua essência, a presença de um "outro" (na concepção da $\mathrm{AD}$, um discurso-outro) que determina, pela relação com a exterioridade, o sujeito da linguagem.

Os trabalhos de Authier-Revuz muito contribuíram para o desenvolvimento da noção de heterogeneidade no seio da $\mathrm{AD}$, mas, como assinalamos anteriormente, Pêcheux, em vários textos, refere-se a não homogeneidade (ao não fechamento) da FD. Um exemplo disso é sua fala no encerramento do Colóquio sobre materialidades discursivas ${ }^{5}$, referindo-se à ausência de fronteiras estáveis entre o interior e o exterior do discurso, entre uma e outra FD, entre o intradiscurso e o interdiscurso. Segundo ele, "o discurso não deve ser entendido como um interior, lugar do dizível e do sentido, rodeado por um exterior, lugar do indizível e do sem sentido". E ainda: "[...] o exterior de um discurso passa a ser pensado não mais como um além de uma fronteira, mas como um aqui, sem fronteiras assinaláveis, como a presença-ausência, eficácia do outro dentro do mesmo sentido" (PÊCHEUX, 1981, p. 199).

No caso em análise, o representante da "voz de Deus", por meio da inserção do discurso-outro, além de divergir da posição de sujeito 2 , prescreve (dá ordens) o que deve ser dito/ser feito, buscando validar o discurso da igreja e submeter os fiéis a esse. Ao fazer isso, marca fortemente o DRC com traços do discurso 
autoritário que, nesse funcionamento discursivo, "sabe" o que deve ser dito/ser feito no interior da FD. "Sabe" também o que precisa ser silenciado em outros dizeres que nela circulam - o silenciamento funciona aí como um processo de interdição de sentidos - são dizeres que não devem, não podem ser ditos no interior da FD do DRC. Conforme Orlandi (1987, p. 246), "no cristianismo, enquanto religião institucional, a interpretação própria é a da Igreja, o texto próprio é a Bíblia...". Daí a possibilidade de compreender que aquilo que foge dessa interpretação é o que deve ser interditado, silenciado, censurado.

Em um primeiro momento, nos enunciados em pauta, o discurso religioso, na busca do convencimento desejado, atravessado pela ilusão do esquecimento número 2 , zona do dizível, do repetível, do formulável - "eu sei o que eu digo" 6 , "seleciona", no interior da FD (no sistema de enunciados), enunciados dizíveis, com os quais estrutura seu texto; mas, ao mesmo tempo, nesse movimento de discurso, emerge um discurso-outro fortemente divergente.

Ainda em relação aos três enunciados, constatamos que o sujeito enunciador "lança mão" de dogmas 7 , tidos como "verdades" incontestáveis/inquestionáveis, na tentativa de qualificar seu discurso e, por conseguinte, negar um outro discurso que circula no interior da FD. Os dogmas podem ser observados em: 1 . ...separe a parte de Deus. ESTE É SEU DÍZIMO; 2. Dízimo é: devolução a Deus do que já é de Deus!. 3. ... retorna para o dizimista, multiplicado por Deus. ESTÁ NA BÍBLIA!.

Realizadas essas considerações em relação aos três enunciados, nosso objetivo, a seguir, é analisar os dois primeiros pelo funcionamento discursivo da negação, e o terceiro, pelo funcionamento discursivo da promessa. Passemos, então, ao primeiro movimento de análise.

1) Não espere sobrar, ao receber a recompensa pelo seu trabalho, primeiro separe a parte de Deus. ESTE É SEU DÍZIMO.

2) Dízimo não é: doação, esmola, ajuda, pagamento, colaboração, oferta ou ato de piedade. Dízimo é: devolução a Deus do que já é de Deus!

Sobre a negação, de início, recorremos a Ducrot (1981, p. 93-104). Na concepção desse autor, os estudos sobre a negação levam a afirmar que os enunciados que a contém apresentam-se fragmentados, levando-o a entender que essa fragmentação ultrapassa o enunciado, constatando, então, que o próprio sujeito apresenta-se fragmentado/dividido. Talvez seja esse $o$ aspecto mais importante na noção de negação de Ducrot para nossa análise: a negação constitui-se de vozes contraditórias, pois realiza, no mínimo, dois atos ilocucionais: um de afirmação (subjacente) que se refere ao discurso de outrem, e outro de explicitação da negação desse discurso ${ }^{8}$.

O proposto por esse autor sobre a negação pode ser deslocado para o âmbito da análise de discurso (AD) que, preocu- 
pada com o efeito de sentido que certos funcionamentos do discurso provocam, examina a negação por meio da noção do enunciado dividido. A noção de enunciado dividido formulada por Courtine (1981, p. 49), nos ajuda a demonstrar a heterogeneidade do discurso, só que, no caso em análise, diferentemente do postulado por esse autor, a relação que se estabelece é uma divergência interna, isso é, entre posições de sujeito que convivem no interior de uma mesma $\mathrm{FD}$, e não entre FDs. Nosso objetivo, então, é compreender, no processo de interlocução, quem ou o quê está sendo negado no referido discurso.

Sobre o enunciado 1 , note-se que o escopo da negação ${ }^{9}$ de "Não espere sobrar" recai sobre a exterioridade do enunciado. Nessa exterioridade da posição-sujeito, pelo viés da categoria de análise da memória discursiva, é possível recuperar enunciados inscritos na posição-sujeito que representa os fiéis (COURTINE, 1981, p. 51-52). São os enunciados dessa posição-sujeito que divergem daqueles do sujeito enunciador, representante da "voz de Deus".

Se no referido cartaz, estivesse escrito: "Ao receber a recompensa pelo seu trabalho, primeiro separe a parte de Deus. ESTE É SEU DÍZIMO”, teríamos aí o efeito de sentido de uma recomendação, ou até mesmo de uma ordem. Qual, então, o porquê da negação - "Não espere sobrar"? No caso, não estamos diante da negação de uma afirmação, e sim da negação de uma condição que pode ser as- sim parafraseada: Se sobrar eu ajudo...; Quando sobrar eu ajudo... Frente a essa discursividade que circula em uma outra posição-sujeito, o sujeito enunciador, representante da "voz de Deus" produz uma espécie de antecipação ao discurso da posição-sujeito 2 .

No processo de antecipação, embora o sujeito não tenha controle sobre seu dizer, pode tirar partido das relações de sentidos de discursos prévios (da ordem do interdiscurso), tentando antecipar o que seu(s) interlocutor(es) vai/vão pensar. A antecipação do que o outro vai pensar, segundo Pêcheux (1990a, p. 77-78), "parece constitutiva de qualquer discurso" e é entendida como o momento em que o orador experimenta, de certa maneira, o lugar do ouvinte a partir de seu próprio lugar de orador. Nesse processo, está implicado o jogo das formações imaginárias (a imagem que faz de $\mathrm{X}$, de si mesmo, do outro $)^{10}$. Ressaltamos, no entanto, que não estamos tratando de um sujeito empírico, de um sujeito dotado de intencionalidade. No âmbito da análise do discurso, a subjetividade constrói-se a partir de um lugar que é social, isso é, marcado pela historicidade e pela ideologia e atravessado pelo inconsciente - o sujeito não é dono absoluto de seu dizer, mesmo que não perceba isso. Na perspectiva discursiva, o sujeito assume um lugar-social, simbólico, na organização das relações humanas, mas não tem consciência disso, pois ele é interpelado pela ideologia e descentrado pelo inconsciente. Assim, no processo de 
interpelação, o sujeito não tem controle sobre o modo como aquilo que enuncia vai significar, isso é, não tem controle sobre como vai atuar seu dizer sobre seu(s) interlocutor(es).

Ainda em relação à antecipação, Orlandi (1998, p. 76) escreve que "cada um 'sabe' prever onde seu ouvinte o espera - é esse jogo imaginário que funciona no discurso". São as formações imaginárias designando lugares que os locutores se atribuem uns aos outros que constituem as condições de produção $(\mathrm{CP})$ do discurso. Assim como as condições de produção, a posição-sujeito e a FD em que se inscrevem o sujeito enunciador e seus interlocutores também é constitutiva do dizer, interferindo na produção de efeitos de sentido. No caso em análise, como já sinalizado, são duas posições-sujeito, inscritas em uma mesma FD - a FD do DRC.

Retomando o enunciado 1, podemos compreender que o sujeito enunciador sinaliza para a interdição de um dizer entendido como não próprio do discurso religioso, o qual se constitui como pré-construído no âmbito do interdiscurso e que emerge, sob a forma de um discurso transverso, no discurso do sujeito enunciador - é essa voz que precisa ser desqualificada. Para produzir esse efeito de desqualificação do discurso-outro o representante da "voz de Deus" "lança mão" de dogmas que aí funcionam como marcas linguísticas que nos levam a formular uma possível estrutura dos enunciados: "Não espere X, separe Y";
"Y é Z". Observemos: Não espere sobrar (não espere $\mathrm{X}$ ), primeiro separe a parte que é de Deus (separe Y). Este é seu dízimo (Y é Z) ${ }^{11}$.

Passemos então para o segundo enunciado, no qual também ocorre a negação de um discurso-outro, porém, o funcionamento discursivo é diferente, pois o discurso negado está explícito no da posição-sujeito 1 . Trata-se da negação direta de um discurso-outro. Nesse enunciado, o escopo da negação recai sobre o que "não é", ou seja, aquilo que não se pode considerar como sendo próprio do discurso da Igreja. O efeito de sentido dessa negação explícita e direta acaba por se constituir como (re)afirmação de saberes inscritos na posição-sujeito em que o sujeito enunciador está inscrito (a posição-sujeito 1 , representante da "voz de Deus" a qual dá o norte de "como deve ser"). Dizendo de outra maneira, esse emissário da "voz de Deus" diverge do discurso da posição-sujeito 2 e, ao mesmo tempo, redireciona o discurso para o que a Igreja Católica acredita ser o dízimo. Evidencia-se assim, mediante esse funcionamento discursivo da negação, uma heterogeneidade no enunciado, que atesta a não homogeneidade do discurso no interior da FD do DRC.

Os dois enunciados caracterizam-se como enunciados divididos a partir do quais, pelas marcas linguísticas do modo imperativo afirmativo (enunciado 1) e da negação explícita (enunciado 2), podemos produzir o efeito de sentido de reafirmação, de ordem, de instrução dos 
valores da igreja, mas também podemos compreender aquilo que a posição-sujeito 1 entende que deve ser interditado, silenciado. O que "não é/não pode ser dito" consiste no interdito. Observemos que os enunciados poderiam ser parafraseados por: em 1) Há uma parte de seu salário que deve ser entregue a Deus como pagamento do dízimo; em 2) Dízimo é devolução a Deus do que já é de Deus! - isso já daria conta de explicitar a concepção da igreja sobre a questão em pauta. Então, o porquê da negação presente nos enunciados, como ela funciona no processo discursivo? No nosso entendimento, nega-se justamente o que "não deve ser dito" ou o que "não pode ou não convém que continue sendo dito" pelos fiéis que seguem a religião - a negação funciona, então, permitindo a produção de um efeito de sentido de interdição.

Esse posicionamento leva-nos aos escritos de Foucault (1996, p. 10) quando, ao pronunciar sua aula inaugural no Collège de France, enfatiza o fato de que, na sociedade, estão presentes procedimentos de exclusão. Dentre esses procedimentos, destaca o de interdição. Segundo o filósofo, "sabe-se bem que não se tem o direito de dizer tudo, que não se pode falar de tudo em qualquer circunstância, que qualquer um, enfim, não pode falar de qualquer coisa" (op. cit., p. 9). Ressalta ainda que "tabu do objeto, ritual da circunstância, direito privilegiado ou exclusivo do sujeito que fala se constituem como o jogo de três tipos de interdição". Ainda de acordo com o professor, esses três tipos de interdição se cruzam, se reforçam ou se compensam formando uma grade complexa sempre em processo de modificação, formando uma espécie de "buraco negro" que estamos tentando associar ao que "não pode, não deve, não convém ser dito" da AD. Imbricam-se, portanto, as relações de poder e de desejo que regulam o funcionamento dos discursos em geral (op. cit., p. 9-10) com o que é interditado no interior de uma formação discursiva na $\mathrm{AD}$, no caso a FD do DRC.

Registramos que, embora o funcionamento discursivo desses dois enunciados não seja exatamente o mesmo, a heterogeneidade discursiva está presente em ambos e podemos explicitá-la pelo enunciado dividido. Courtine (1981, p. 49) definiu o enunciado dividido como sendo aquele caracterizado pelo uso contrastivo da cópula de identificação "é/não é". Nos trabalhos de análise que vêm sendo realizados no Brasil, também temos usado essa noção para demonstrar a diferença e/ou divergência no interior de uma mesma FD. Em trabalho (CAZARIN, 1998, p. 111) entendemos a diferença como diversidade, variedade de posições de sujeito que não são iguais, mas convivem pacificamente num mesmo domínio de saber, ao passo que a divergência é tomada como discordância, ou seja, como posições de sujeito que se afastam progressivamente. Convivem no mesmo domínio de saber, mas em permanente tensão. Observemos então os referidos enunciados sob a forma de enunciado dividido. 
No enunciado 1, teríamos:

X Ao receber seu salário, primeiro separe a parte que é de Deus esse é seu dízimo.

E

Y Ao receber meu salário, se sobrar, pago o dízimo.

Já, no enunciado 2, teríamos:

X Dízimo é: devolução a Deus do que já é de Deus!

$\mathrm{E}$

Y Dízimo é: doação, esmola, ajuda, pagamento, colaboração, oferta ou ato de piedade.

Nos dois enunciados divididos, Y representa o discurso-outro (o da posição-sujeito 2). A diferença é que, no primeiro, foi preciso acionar a categoria da memória discursiva para compreender o efeito do pré-construído; já no segundo, o discurso-outro está explícito no próprio enunciado. De qualquer forma, o Y representa algo pertencente a uma posição-sujeito divergente daquela representada por X, que remete aos saberes próprios da "voz de Deus".

$\mathrm{O}$ sujeito enunciador, representante da "voz de Deus" (está no lugar de... ${ }^{12}$ ), no primeiro enunciado, recupera, no interdiscurso, enunciados pré-construídos, já proferidos e significados anteriormente e os (re)significa. Já no segundo enunciado, a exterioridade, o já-lá do interdiscurso está explicitado no próprio enunciado, mas marcado como o que não pode/não deve ser dito no interior da FD do discurso religioso católico - é esse dizer que deve ser interditado.

A partir daqui, nosso interesse é examinar como funciona, no discurso religioso, a promessa que entendemos estar presente no enunciado 3.

3. "Todo o dízimo, apresentado no altar, retorna para o dizimista, multiplicado por Deus. ESTÁ NA BÍBLIA!"'13.

Em relação a esse enunciado, Foucault escreve que o ritual não só define a qualidade dos indivíduos que falam, mas também os gestos, os comportamentos, as circunstâncias e todo o conjunto de signos que devem acompanhar o discurso. É o ritual que "fixa, enfim, a eficácia suposta ou imposta das palavras, seu efeito sobre aqueles aos quais se dirigem, os limites de seu valor de coerção". Dentre outros ${ }^{14}$, salienta os discursos 
religiosos, dizendo que os mesmos "não podem ser dissociados dessa prática de um ritual que determina para os sujeitos que falam, ao mesmo tempo, propriedades singulares e papéis preestabelecidos" (FOUCAULT, 1996, p. 39).

Tendo presente o escrito pelo autor recém-citado, interessa-nos compreender como funciona a promessa no discurso religioso. Em texto distinto (2005, p. 314-315), examinamos o funcionamento discursivo da promessa no discurso político, no qual constatamos que o mais relevante na promessa é a projeção de futuro, a qual tem relação com o que escreve Miguel (2000, p. 28), quando trata do "mito e do discurso político"; quando sinaliza para o fato de que o discurso político, "embora se utilize do passado e o redesenhe permanentemente, se projeta com muito mais frequência em direção ao futuro".

No caso em pauta, entendemos que a posição-sujeito 1 identificada com a "voz de Deus", embora usando o tempo presente, também produz um efeito de futuro - promete e, ao mesmo tempo, busca o convencimento de seus interlocutores - os fiéis - por meio daquilo que apresenta como verdade absoluta (dogma) - Está na Bíblia! Esta, segundo Orlandi (1987, p. 246), é tida como "a revelação da palavra de Deus".

Entendemos que entre o funcionamento do discurso político e o do discurso religioso há, no mínimo, uma semelhança - tanto em um, quanto em outro, a promessa pode não se concretizar - é projeção de futuro. Entretanto, também existem diferenças entre o funcionamento desses dois discursos - enquanto no discurso político, a promessa funciona como possibilidade de um vir a ser do discurso, no discurso religioso, devido à presença de dogmas, a mesma é apresentada como algo certo, uma certeza, já dada - ESTÁ NA BÍBLIA! O discurso religioso, pelo menos no que está em análise, tanto joga com a projeção de futuro como com a memória do que já está posto, prescrito, ou seja, com o que - ESTÁ NA BÍBLIA! Como algo que não pode ser questionado.

Assim, a presença do dogma no discurso religioso não funciona apenas como argumento para a promessa, pois, no nosso ponto de vista, acaba produzindo o efeito de sentido de punição, ainda que essa repreensão seja entendida como a ausência de bênçãos. Para os que creem, o discurso religioso funciona como promessa e a fé, nesse caso, é um índice de não reversibilidade (ORLANDI, 1987, p. 251). Já para os que não creem, funciona como ameaça ou como uma possibilidade de "punição" futura.

De acordo com Pêcheux (1988, p. 262), “...as palavras não significam a priori...”, pois, para compreendê-las não basta observar o contexto nos quais são atualizadas; na perspectiva teórica da $\mathrm{AD}$, é necessário mais do que isso - é preciso analisá-las a partir do processo discursivo em que ocorrem para compreender como funcionam e que efeitos de sentido produzem. Além disso, ensina-nos 
que toda a FD reflete pela linguagem a formação ideológica (FI) que lhe subjaz. Esta é compreendida como “... um conjunto complexo de atitudes e de representações que não são nem 'individuais' nem 'universais', mas se relacionam mais ou menos diretamente a posições de classe em conflito umas com as outras..." (PÊCHEUX \& FUCHS apud GADET \& HAK, 1990b, p.166, grifos dos autores). Isso nos permite escrever que todo discurso inscreve-se em uma FD que, por sua vez, representa na linguagem uma FI, e os efeitos de sentido por ele produzidos são projetados na linguagem no interior da FD, conferindo sentido ao discurso proferido pelo sujeito, a partir da posição-sujeito em que se inscreve. A ideologia, portanto, é constitutiva do discurso, mas também do sujeito e dos sentidos. No entanto, os saberes de uma FD não são homogêneos e, em seu interior, há espaço para a contradição, para a diferença e para a divergência.

Reiteramos que nas análises realizadas foi possível constatar o modo como as condições de produção do discurso estabelecem-se e como funcionam as relações de força entre distintas posições sujeito no interior da FD do DRC. No caso, a posição sujeito 1 marca seu dizer com a força da locução que este lugar representa - fala no lugar da "voz de Deus"!

Por último, tendo em conta que a movência de sentidos e de sujeitos é uma constante, não temos a pretensão de dar por encerrada essa discussão. Outras interpretações são sempre possíveis, outros sentidos podem ser produzidos a partir desses mesmos enunciados.

\author{
The discursive functioning \\ of denial and promise in the \\ religious discourse
}

\section{Abstract}

This text is concerned with the discursive functioning analysis of denial and promise in the Catholic religious discourse. The corpus is exposed enunciates in a poster about the faithful obligations to pay the tenth putted in Sé' Basilica Cathedral of Our Lady Assumption, in Mariana, MG, in 2003. The analysis put in evidence the difference between two subject-positions inside of a same discursive formation.

Keywords: Deny. Promise. Discursive formation. Subject-position. Interdiction.

\section{Notas}

1 Uma versão preliminar deste texto foi apresentada no III Seminário Nacional de Linguística e Ensino de Língua Portuguesa - Universidade Federal de Rio Grande - FURG, novembro de 2011.

2 No Dicionário Houaiss de Língua Portuguesa (2001), encontramos "dízimo" como uma palavra de origem latina - decímus/decúmos $>$ décima parte. Duas possibilidades de significação nos interessam 1. "Histórico tributo que os fiéis pagavam à Igreja como obrigação religiosa"; e "contribuições doadas pelos fiéis aos Vigários das paróquias" (Op. cit., p. 1067).

3 Entendemos as relações de divergência como aquelas em que, no interior da FD, acontecem entre a posição de sujeito 1 e a posição de sujeito 2 , ocupada por uma posição de sujeito que, 
na relação que estabelece com a forma-sujeito da FD do DRC, diverge da posição do sujeito enunciador do discurso. Tanto as relações de diferença quanto as relações de divergência são resultado de formas distintas de relacionamento com a forma-sujeito da FD. Não se trata aqui de relações de diferença que também podem ocorrer no interior de uma FD; no caso em pauta, estamos trabalhando apenas com posições divergentes. A distinção entre umas e outras consiste no acirramento da diferença que se acentua a ponto de tornar-se divergência. A diferença passa por uma espécie de gradação, isto é, o discurso se torna tão tenso a ponto de apresentar-se como divergente. Tanto na diferença, quanto na divergência os enunciados convivem em uma mesma FD, mas apontam para o fato de que ela não é idêntica a si mesma, pois possui espaço para a contradição e para a heterogeneidade discursiva (CAZARIN, 1998, p.111).

4 A heterogeneidade constitutiva é aquela que não pode ser analisada. Ela é constitutiva do discurso enquanto o sujeito não tem condições de se dar conta das outras vozes as quais recorre para pronunciar um discurso que toma com o seu (homogêneo). É por meio da interdiscursividade e da intersubjetividade que as palavras do "outro" vão ser inscritas no discurso. Segundo Authier (1982, p. 141), esse "outro", no entanto, "não é um objeto exterior do qual se fala, mas uma condição constitutiva do discurso de um falante que não é a fonte primeira desse discurso". Já a heterogeneidade mostrada difere da constitutiva pelo aspecto de ser passível de análise, estabelecendo ainda, como concebe Authier, uma relação de negociação com a heterogeneidade constitutiva, ou com o interdiscurso. A possibilidade de análise se dá pelo fato de que a palavra do "outro" é inscrita visivelmente no discurso. Esse rompimento da aparente homogeneidade discursiva não representa um espelho visível da heterogeneidade constitutiva do discurso, mas, também não é algo independente desta.

5 O Colóquio materialidades discursivas foi realizado entre 24-26 abril 1980, na Universidade Paris X - Nanterre - e publicado pela Presses Universitaires de Lille, 1981; dele participaram, dentre outros, Michel Pêcheux, Jean Jacques Courtine, Marandan, Milner, Ansart.

6 Essa zona (esquecimento nํㅜㄹ) está em oposição a uma outra (ao esquecimento $\mathrm{n}^{\circ} 1$ ), que consiste em uma zona inacessível ao sujeito e que é de natureza inconsciente; zona do "recalcado", constitutiva da subjetividade - o sujeito é afetado por esse esquecimento, mas acredita ser fonte e senhor de seu dizer (PÊCHEUX, M. 1990추, p. 168-169).

7 Um dogma, segundo o Dicionário Houaiss (2001), consiste: 1. "num ponto fundamental de uma doutrina religiosa, apresentado como certo e indiscutível, cuja verdade se espera que as pessoas aceitem sem questionar"; 2 . qualquer doutrina (filosófica, política, etc) de caráter indiscutível em função de supostamente ser uma verdade aceita por todos; 3. [...] (Op. cit., p.1071).

8 A negação descritiva recorre à noção de negação de constituinte ou de frase, bem como às questões propostas por lógicos e filósofos da linguagem no que se refere a estar se afirmando um conteúdo negativo com um ato ilocucional positivo. Ducrot define, então, uma negação descritiva como sendo "uma afirmação de um conteúdo negativo sem referência a uma afirmação antitética (pode-se ter, então, tanto uma negação de frase como uma negação de predicado)" (1981, p. 98). A negação polêmica é definida com base na Teoria dos atos de fala, principalmente na noção de ato ilocucional. Para o autor, uma negação polêmica corresponde a "um ato de fala de negação, e que se apresenta, pois, como refutação do enunciado positivo correspondente (trata-se sempre, nesse caso, de uma negação de frase)" (1981, p. 98). Segundo Ducrot, ao refutar um enunciado anterior, o locutor está tendo uma atitude psicológica de negar. Uma negação de frase recai sobre uma frase antitética que funciona como uma negação metalinguística, feita sobre um enunciado anterior, que pode ter sido dito, estar subentendido ou pressuposto no diálogo.

9 "O escopo da negação define-se como o segmento de enunciado em que a negação exerce seu efeito, ou seja, como conjunto de conteúdos afetados pelo operador de negação" (MOURA NEVES, 2000, p. 285).

10 Em AD, "lugar social" não significa um feixe de traços objetivos, e sim funciona, nos processos discursivos, como uma série de formações imaginárias que designam o lugar que $\mathrm{Ae} \mathrm{B}$ se atribuem cada um a si e ao outro - a imagem que fazem de seu próprio lugar e do lugar do outro; lugar, também, não tem a ver com a realidade física, mas com um objeto imaginário. Daí uma série de questionamentos poderiam ser realizados, indicando a posição dos protagonistas do 
discurso: quem sou eu para lhe falar assim? Quem é ele para que eu lhe fale assim? Quem sou eu para que ele me fale assim? Quem é ele para que me fale assim?...(PÊCHEUX, 1990a, p. 81-83).

11 Para efeitos metodológicos, estamos utilizando $\mathrm{Y}=$ sobrar; $\mathrm{X}=$ parte que é de Deus; $\mathrm{Z}=$ dízimo.

12 Orlandi escreve que "o representante, ou seja, aquele que fala do lugar de Deus transmite Suas palavras, mas não se confunde com Ele, não é Deus"(1987, p. 253).

13 As palavras que estão em maiúsculas retratam a forma como estavam escritas no cartaz.

14 Judiciários, terapêuticos e políticos.

\section{Referências}

AUTHIER-REVUZ, Jacqueline. Hétérogénéité montrée et hétérogénéité constitutive: elements pour une approche de l'autre dans le discours. DRLAV (26): 91-151, 1982.

CAZARIN, Ercília Ana. Heterogeneidade discursiva: relações e efeitos de sentido instaurados pela inserção do discurso-outro no discurso político de L. I. Lula da Silva. Ijuí, RS: Ed. UNIJUI, 1998.

- Identificação e representação política: uma análise do discurso de Lula. Ijuí, RS: Ed. UNIJUI, 2005.

COURTINE, Jean Jacques. Quelques problèmes theoriques et methodologiques en analyse du discours; à propos du discours communiste adressé aux chrétiens. Langages (62), juin, 1981.

DUCROT, Oswald. Provar e dizer: linguagem e lógica. Tradução de Maria Aparecida Barbosa, Maria de Fátima Gonçalves Moreira, Cidmar Teodoro Pais. São Paulo: Global Ed., 1981.

FOUCAULT, Michel. A ordem do discurso. Tradução Laura Fraga de Almeida Sampaio. $3^{\text {a }}$ ed. São Paulo, SP: Edições Loyola, 1996.

GADET, Françoise \& PÊCHEUX, Michel. La lengua de nunca acabar. Traducido por Beatriz Job. México: Fondo de Cultura Económica, 1984.
HOUAISS, Antônio e VILLAR Mauro Salles. Dicionário Houaiss de Língua Portuguesa. Rio de Janeiro: Objetiva, 2001.

LEANDRO FERREIRA, Maria Cristina. $D a$ ambiguidade ao equívoco: a resistência da língua nos limites da sintaxe e do discurso. Porto Alegre: Editora da UFRGS, 2000.

MILNER, Jean-Claude. Introduction à une Science du Langage. Paris: Éditions du Seuil, 1989.

MIGUEL, Luís Felipe. Mito e discurso político - uma análise a partir da campanha eleitoral brasileira de 1994. Campinas, SP: Editora da UNICAMP; São Paulo, SP: Imprensa Oficial, 2000.

MOURA NEVES, Maria Helena. Gramática de usos do português. São Paulo: Editora da UNESP, 2000.

ORLANDI, Eni Puccinelli. A linguagem e seu funcionamento: as formas do discurso. 2. ed. rev. e aum. Campinas, SP: Pontes, 1987.

Discurso e argumentação: um observatório do político. In Fórum Linguístico, Florianópolis, SC: nº 1 (73-81), jul-dez., 1998.

Análise de discurso: princípios e procedimentos. 3 ed. São Paulo: Pontes, 2001.

PÊCHEUX, Michel. "Table ronde discours histoire-langue". In Colóquio sobre materialidades discursivas. 24-26 abril 1980 - Universidade Paris X - Nanterre - Publicação de Presses Universitaires de Lille, 1981.

Semântica e discurso [1975]. Tradução de Eni Puccinelli Orlandi...[et.al.].Campinas, SP: Ed. da UNICAMP, 1988.

A propósito da análise automática do discurso: atualização e perspectivas (1975). Tradução Bethânia S. Mariani...[et.al.]. In: GADET \& HAK (Orgs.). Por uma análise automática do discurso. Campinas, SP: Ed. da UNICAMP, 1990a.

PÊCHEUX, Michel \& FUCHS, Catherine. [1975]. A propósito da análise automática do discurso: atualização e perspectivas. Tradução Péricles Cunha. GADET \& HAK (Orgs.). In: Por uma análise automática do discurso. Campinas, SP: Ed. da UNICAMP, 1990b. 